\title{
Teaching hydrogeology in the field: the bottleneck in student conceptual model development
}

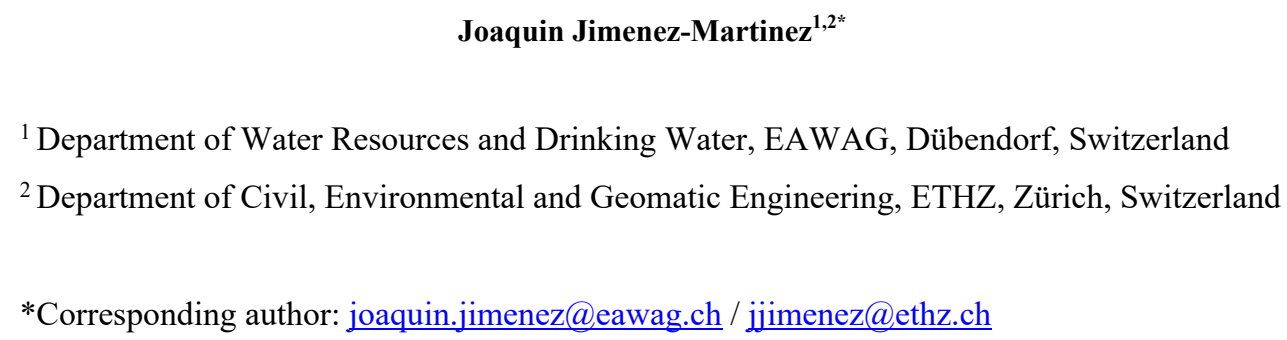

\section{Introduction}

Groundwater hydrology, or hydrogeology, is an applied science driven by the current anthropically induced environmental challenges with a markedly interdisciplinary nature at the interface between geology, hydrology, hydraulics, soils science, physics and chemistry, and more recently biology (Hakoun et al., 2013; Lyon et al., 2013). Therefore, training future 
34 hydrogeologists presents several challenges: $i$ ) subsurface processes are abstract phenomena

35 that are neither visible nor can they be directly experienced (Unterbruner et al., 2016), ii) students that enter a classroom have diverse course backgrounds and preconceptions of basic concepts, and iii) teaching strategies that accommodate new disciplines and concepts while still highlighting basic concepts are lacking (Lyon et al., 2013). Earth and environmental sciences are growing more interdisciplinary and complex (Wood and Wood, 2014), making the shift to a more integrated pedagogy a critical next step in the training of our next generation of environmental thinkers (Gleeson et al., 2012).

A recurrent problem in teaching hydrogeology, particularly in the field, is the difficulty for the students to establish a conceptual model of the functional processes present at the studied area or site. Students come either to class or to the field with preconceived models, i.e., mental models, which frequently deviate in form from the conceptual models on which lessons are based (Vosniadou, 2013). These preconceptions can be resistant to a conceptual change and thus impede the development of further or more accurate knowledge (Unterbruner et al., 2016). Lecturers, which often are scientists, implicitly assume that we understand the functioning of a system if we a have a conceptual and/or computer model that explain or even predict the observations, the so-called scientific model (Bredehoeft et al., 2005; Vicsek 2017). However, scientists should be aware that learning cannot be understood as the replacement of an incorrect by a correct concept (Vosniadou, 2007). Nevertheless, engaging students through the scientific regular practices is recommended to help with a conceptual change (She et al., 2004).

A common teaching issue in hydrogeology and for the development of conceptual models relies on the heterogeneity in the prior knowledge of the enrolled students, especially in master degree programs. For simultaneously teaching students from civil and environmental

60 engineering, biology, geology, chemistry, or physics a strategy of teaching involving lecture,

61 field and practical classes appears like the most common option (Blöschl et al., 2012; Hakoun

62 et al., 2013). If the lecturers pay attention to the prior knowledge of the students, which

63 evolves in time (Gleeson et al., 2012), it has been demonstrated that learning is enhanced

64 (Bransford et al., 1999). As a consequence of the broad range of background, it is necessary

65 to provide students with the appropriate basics in groundwater, including flow and transport

66 processes (Gleeson et al., 2012; Hakoun et al., 2013), before subsequent field and practical

67 courses are taught. 
69 Hydrogeology deals with processes occurring outside the classroom, inviting active-learning methods to complement lectures (Hakoun et al., 2013; Lyon et al., 2013; Van Loon, 2019). While classroom lectures are typically lecturer-centered (students more passive), active

72 learning is student-centered as the instructor acts as a 'facilitator' as the students 'learn by

73 doing' (Pathirana et al., 2012). Teaching through a learning-by-doing strategy has been

74 demonstrated to increase student learning in hydrology and other applied sciences (Lee, 1998; Gates et al., 1996; Noll, 2003; Prince and Felder, 2006; Cutrim et al., 2006; Thompson et al., 2012) and as well as student satisfaction (Laird et al., 2008). Specifically, inquirybased learning should be utilized by instructors to enhance student understanding and develop their cognitive skills (Prince and Felder, 2006; Sell et al., 2006; Hakoun et al., 2013). Inquiry is a characteristic practice in science (Rowell and Ebbers, 2004), and studies have demonstrated the advantages of the learning-by-doing strategy, including inquiry-based learning (Pawson and Teather, 2002; Sell et al., 2006; Coe and Smyth, 2010). However, these teaching strategies also present inherent difficulties. The success of an inquiry-based strategy relies on the active engagement of each student (Prince and Felder, 2006). Some studies have highlighted how a learning-by-doing strategy can risk the perpetuation of inaccurate preestablished concepts (Fuller et al., 2000). Finally, field courses based on a learning-by-doing strategy face difficulties adapting available resources (i.e., site or instruments, between many others) to the students' learning. Therefore, in hydrogeology field courses, it is important to combine in-situ lecture-based explanations (theoretical knowledge) with inquiry-based learning (data gathering, analysis and interpretation). This, along with the acquisition by the students of communication skills with multiple representations, can support the development of higher quality conceptual models. from an inquiry-based learning strategy used in a hydrogeology field course, and the effectiveness of the proposed inquiry-based learning in the conceptual model expressions by the students. We hypothesize that the students' prior knowledge would control their performance in the outcome from the inquiry-based learning proposed, and both the prior experimental site. 
102

\section{Conceptual versus mental model}

While a conceptual model is an external and simplified representation based on scientific knowledge of a system and/or its functioning (Norman 1983), a mental model is internal, personal, idiosyncratic and commonly incomplete representation of a system and/or its functioning (Horton, 1915; Greca and Moreira, 2000). The assumption that conceptual models taught to students should be learned by them and used to make a relation with the theory is not necessarily true (Greca and Moreira, 2000). Students bring their mental models both to the theoretical and practical (field and laboratory) lessons, and lecturers often assume that these mental models will evolve into accurate conceptual models (Norman, 1983; Duit and Glynn, 1996). If such evolution is successful, the student then has the correct theoretical basis with which to understand physical phenomena. However, students do not always understand conceptual models, even when the models are presented correctly, because many students do not have the necessary background. When approached with a conceptual model, students may instead extract only those elements they consider relevant and incorporate them to their mental model, resulting in a mental model that differ from the conceptual model presented (Greca and Moreira, 2000).

Teaching hydrogeology, and in particular teaching hydrogeology in the field, presents the challenge of increasing the students' spatial reasoning abilities. Spatial reasoning abilities, i.e., spatial visualization, contribute substantially to the development of appropriate mental models of systems and processes such as those found in groundwater (Dickerson et al., 2007). For example, visual penetration ability, i.e., the ability to visualize what exist inside a structure, is a key skill aiding the appropriate conceptual understanding of geologic structures (Kali and Orion, 1996; Kali et al., 1997). Therefore, the development of students' spatial reasoning skills, e.g., through numerical modelling (Greca and Moreira, 2000; Bredehoeft et al., 2005), should be considered when abstract groundwater concepts are taught.

\section{Groundwater field course}

\subsection{Course context and field site}

The Groundwater Field Course is offered annually as part of the master curriculum in Environmental Engineering at ETH Zürich. In 2019, this four-day (3 days in the field, 1 day in the lab) intensive course included a total of 17 students ( 7 male, 10 female). While the majority of these students (76\%) attended the Groundwater course (theory and modelling) right before the Field Course, the different academic paths followed by each student resulted 

the individual students enrolled (Table 1).

Table 1. Students' course background. Selected courses include: geology, G; sedimentology and stratigraphy, S/S; geomorphology, GM; geochemistry, GC; geotechnical engineering, GE; hydrology, H; hydrogeology, HG; soil and vadose zone, S/VZ; water resources management, WRM; hydraulics, HYD; geographical information systems, GIS; cartography, C; and forest and landscape, F/L. Prior knowledge rank: low, L; and high, H.

\begin{tabular}{|c|c|c|c|c|c|c|c|c|c|c|c|c|c|c|c|c|}
\hline \multirow{2}{*}{ Student } & \multicolumn{14}{|c|}{ Courses background } & \multirow{2}{*}{ Total } & \multirow{2}{*}{$\begin{array}{c}\text { Piror } \\
\text { knowledge } \\
\text { rank }\end{array}$} \\
\hline & $\mathbf{G}$ & $\mathbf{S} / \mathbf{S}$ & GM & GC & GE & GP & H & HG & $\mathrm{S} / \mathrm{VZ}$ & WRM & HYD & GIS & $\mathrm{C}$ & F/L & & \\
\hline 1 & $x$ & & & & & & $x$ & $x$ & & $x$ & $x$ & $x$ & & & 6 & $\mathrm{H}$ \\
\hline 2 & & & & & & & $\times$ & & $x$ & $x$ & & $x$ & & & 4 & $\mathrm{~L}$ \\
\hline 3 & $x$ & & & & & & $\times$ & $x$ & & $x$ & $x$ & $x$ & & & 6 & $\mathrm{H}$ \\
\hline 4 & $x$ & & $x$ & & & & $x$ & $x$ & & $x$ & $x$ & $x$ & & & 7 & $\mathrm{H}$ \\
\hline 5 & $x$ & & & & $x$ & & $x$ & $x$ & & $x$ & $x$ & $x$ & & & 7 & $\mathrm{H}$ \\
\hline 6 & $x$ & $x$ & & $x$ & $x$ & & $x$ & $x$ & $x$ & $x$ & & $x$ & $x$ & $x$ & 11 & $\mathrm{H}$ \\
\hline 7 & $x$ & & & & & & $\times$ & $x$ & & $x$ & $x$ & $\times$ & & & 6 & $\mathrm{H}$ \\
\hline 8 & & & & & $x$ & & $x$ & $x$ & & $\times$ & $x$ & $x$ & & & 6 & $\mathrm{H}$ \\
\hline 9 & $x$ & & & $x$ & $\times$ & & $x$ & $x$ & $x$ & $x$ & $x$ & $\times$ & & & 9 & $\mathrm{H}$ \\
\hline 10 & $x$ & & & & & & $x$ & $x$ & & & $x$ & $x$ & & & 5 & $\mathrm{~L}$ \\
\hline 11 & & & & & & & $\times$ & $x$ & & $x$ & $x$ & $x$ & & & 5 & $\mathrm{~L}$ \\
\hline 12 & & & & & $x$ & & $x$ & & & $x$ & $x$ & & & & 4 & $\mathrm{~L}$ \\
\hline 13 & $x$ & $\times$ & & & & $x$ & $\times$ & $x$ & $x$ & $\times$ & & $\times$ & & & 8 & $\mathrm{H}$ \\
\hline 14 & $x$ & & & & $x$ & & $x$ & $x$ & & $x$ & $x$ & $x$ & & $x$ & 8 & $\mathrm{H}$ \\
\hline 15 & & & & $x$ & $x$ & & $x$ & $x$ & $x$ & $x$ & $x$ & $x$ & & $x$ & 9 & $\mathrm{H}$ \\
\hline 16 & & & & & & & $\times$ & $x$ & & $x$ & $x$ & $x$ & & & 5 & $\mathrm{~L}$ \\
\hline 17 & & & & & & & $x$ & $x$ & & $x$ & & $x$ & & $x$ & 5 & $\mathrm{~L}$ \\
\hline
\end{tabular}

144 The Field Course is carried out in Kappelen, Canton Bern, Switzerland, a test site initiated in

1451996 (Flynn, 2004). The Kappelen field site is located $15 \mathrm{~km} \mathrm{NW}$ of the city of Bern, in the

146 proximity of the village Lyss. The site is a flat wooded terrain bounded to the west by agricultural land and to the east by a motorway and the river Alte Aare (Figure 1).

148 Underneath the surface of this terrain is approximately $16 \mathrm{~m}$ of unconsolidated gravels,

149 which includes to a lesser extent sand and silt (with a hydraulic conductivity of $\sim 1 \cdot 10^{4} \mathrm{~m} / \mathrm{s}$ ).

150 These gravels overlie a unit of fine-grained sands and silt/clay (with and hydraulic conductivity ranging from $5 \cdot 10^{4}$ to $1 \cdot 10^{2} \mathrm{~m} / \mathrm{s}$ ) (Oyono, 1996). The site includes a monitoring well network (approximately $90 \times 60 \mathrm{~m}^{2}$ ) consisting of seven $100 \mathrm{~mm}$ diameter well pairs.

153 Wells set in the shallow part of the underlying aquifer have 3 to $4 \mathrm{~m}$ long well screens set approximately from 4 to $8 \mathrm{~m}$ below ground surface (m BGS), while those set in the deep part of the aquifer have a 3 to $5 \mathrm{~m}$ long well screens, screened at 10 to $16 \mathrm{~m} \mathrm{BGS}$. Two additional

156 deep wells constructed with identical characteristics, complete the network. The site gives students who might not traditionally have conducted fieldwork the opportunity to spend time in the field learning about field work methods (Blöschl et al., 2012). 

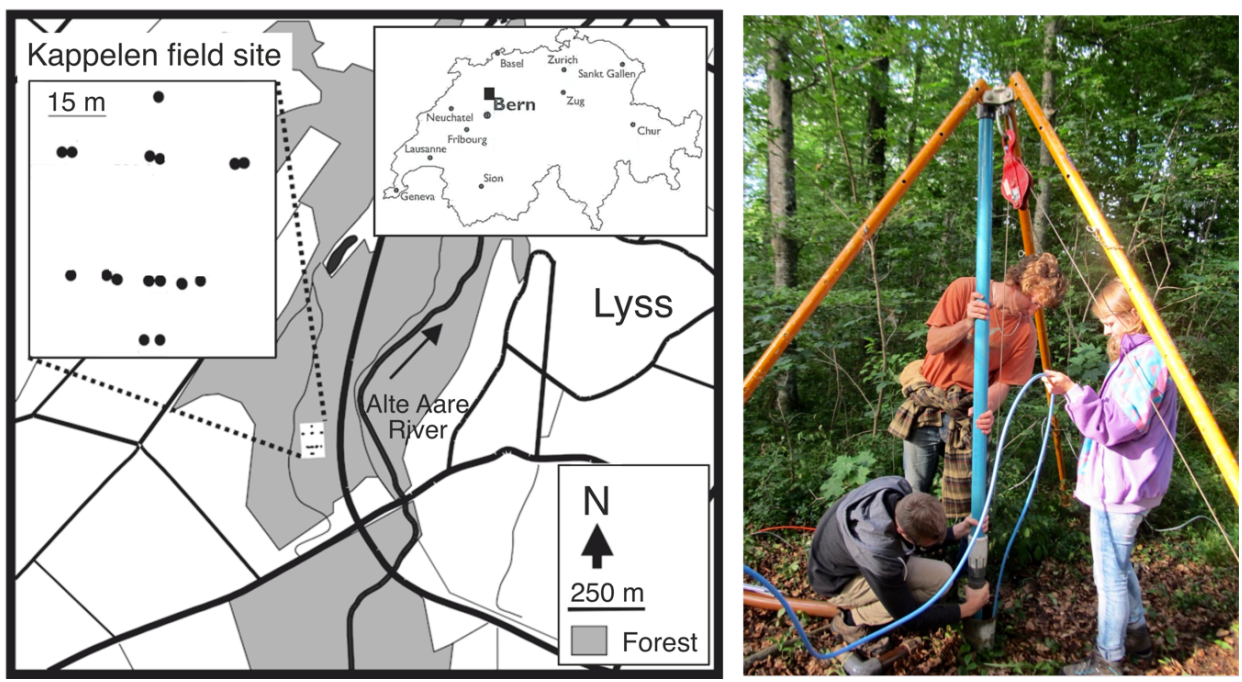

Figure 1. Left: location map for the Kappelen field site (Canton Bern, Switzerland) and detail of monitoring well locations. Right: students in the setting up phase of a pumping test.

160

\subsection{Teaching approach}

The Field Course provides students the opportunity to engage in active learning experiments, through which the students collect, analyze and interpret data. This inquiry-based learning gives students ownership over their learning and excellent vocational training (Gleeson et al., 2012). The students are encouraged to work in groups (i.e., collaborative learning, group work towards a common goal) (Millis and Cottell Jr., 1997; Allen et al., 2001) and are responsible for formatting their own experimental designs. Because experiments are less likely to confer theoretical knowledge (Sanders, 1998), Field Course instructors continuously seek establish links between the field content and the theoretical concepts taught in the classroom (Groundwater course, theory and modelling).

The course is organized in three modules: soil and vadose zone processes, groundwater flow processes, and groundwater transport processes. In the soil and vadose zone module, students are asked to characterize soil physical and chemical properties, determine the soil water retention function at different depths, determine the infiltration capacity of the site, and quantify aquifer recharge. In the module on groundwater flow processes, students learn about the piezometric map and temporal evolution, to determine vertical profiles of temperature and electrical conductivity, and to parameterize the hydraulics of the aquifer (flow meter test, dilution test, pumping test, and slug test). Finally, in the module on groundwater transport processes, students perform a tracer test and a dual pumping test for hands-on experience 

module, the students are asked to identify the uncertainties related to each field method. After three days in the field, the students complement their gathered data sets with soil and water chemistry related data during a final day in the laboratory. Student performance is then evaluated via a written report due 35 days after the end of the course. The evaluation of this report focuses on how well the student interpreted each of the different experiments and integrated their discussion to their results.

Table 2. Organization of an inquiry-based learning strategy, implemented in the Field Course. Outlined, the

190 three different course modules, the experiments in each module, and the final learning assessment.

\begin{tabular}{lll}
\hline \multicolumn{1}{c}{ Module } & \multicolumn{1}{c}{ Experiments } & \multicolumn{1}{c}{$\begin{array}{c}\text { Learning } \\
\text { assessment }\end{array}$} \\
\hline Soil/Vadose zone processes & Soil physical and chemical characterization & \\
& Water retention function & \\
& Infiltration capacity & \multirow{2}{*}{ Written report } \\
& Aquifer recharge & \\
\hline Aquifer flow processes & Piezometric map and temporal evolution & \\
& Temperature and electrical conductivity profiles & \\
& Flow meter test & \\
& Dilution test & \\
& Pumping test & \\
& Slug test & \\
\hline Aquifer transport processes & Tracer test & Dual pumping technique for water sampling (Rapp et al., 1998) \\
& &
\end{tabular}

191

\section{$192 \quad 3.3$ Objectives and experimental design}

193 From the pedagogical data collected from our 2019 Groundwater Field Course, we asked two

194 main questions: $i$ ) does a student's prior knowledge affect their success at inquiry-based

195 learning? and $\mathrm{ii}$ ) does a student's prior knowledge and inquiry-based learning affect their

196 success at developing accurate conceptual models? To address these questions, we defined

197 three main variables based on the methodology proposed by Sell et al. (2006) (Table 3): prior

198 knowledge (PK, see Table 1), inquiry-based learning (IBL, see Table 2) and conceptual

199 model expression (CME). Here, we assessed each student's PK based on the number of

200 courses the student had already completed from a list of 14 courses closely related to

201 hydrogeology (e.g., surface hydrology) and visual representation (e.g., GIS). Each student

202 thus was assigned a PK rank of either low ( $\leq 6$ courses) or high ( $\geq 7$ courses). The remaining

203 two variables were quantified based on each student's scores. Each student's success at

204 inquiry-based learning (IBL) was quantitatively evaluated from a written report [0-6], and 
success at conceptual model expression (CME) was quantitatively evaluated from the conceptual model representation [0-6]. With these variables, we then sought to answer our questions with two types of statistical tests: descriptive and inferential statistics for one sample and a test of statistical relationship between two samples.

Table 3. The definitions and methods of assessment for the three variables describing student understanding:

211 prior knowledge, inquiry-based learning and conceptual model expression. The scoring range, mean and standard deviation (s.d.) of the student scores are reported for each variable.

\begin{tabular}{llll}
\hline Variable & Assesment & Range & Mean (s.d.) \\
\hline Prior Knowledge - PK & Previous courses taken & {$[0-14]$ Low $(\leq 6) ;$ High $(\geq 7)$} & $7(1.95)$ \\
Inquiry-Based Learning - IBL & Scores on written report & {$[0-6]$} & $5(0.31)$ \\
Conceptual Model Expression - CME & Scores on student representation & {$[0-6]$} & $4(0.75)$ \\
\hline
\end{tabular}

\section{Results and discussion}

215 To determine how prior knowledge may affect a student's success in our Field Course, we

216 first computed the mean and standard deviation of each variable describing student understanding: PK, IBL and CME. Between the two variables assessed from report or exam scores (IBL and CME), the students had a lower mean CME score (Table 3). Amongst individual students, CME scores displayed greater variability than IBL scores. One-sample Kolmogorov-Smirnov test of the data set indicated that the variables did not follow a normal distribution in the students' population $(p<0.05)$. Thus, to determine the statistical relationship between two samples (e.g., PK and IBL), we opted to use a nonparametric test, the Mann-Whitney U (or Wilcoxon Rank-Sum) rather than a two-sample $t$-test.

With a Mann-Whitney $U$ test, we then tested whether student success at inquiry-based learning and at conceptual model expression was related to prior knowledge (Table 4). The test indicated a no significant difference $(p>0.05)$ in the variable IBL between the students with high and low PK. On the contrary, a significant difference $(p<0.05)$ was observed between the students with high and low PK for the variable CME. Therefore, while the IBL average scores for the two PK groups (i.e., High-PK and Low-PK) can be considered statistically the same, this is not the case for the CME average scores of the two PK groups.

232 In other words, while the students' prior knowledge was not important in the outcomes from the inquiry-based learning, the score obtained by the students in the conceptual model

234 expression was dependent on the prior knowledge. 
Table 4. Differences of the mean and standard deviation (s.d.) of the student scores between PK (prior knowledge) groups (high and low) for the variables IBL (inquiry-based learning) and CME (conceptual model expression). The Mann-Whitney U test was used to determine the significance of the relationship between the two PK groups for each variable.

\begin{tabular}{llccc}
\hline Variable & PK & Difference mean & Difference s.d. & Significance $(\boldsymbol{p}<\mathbf{0 . 0 5})$ \\
\hline IBL & High-Low & 0.14 & -0.06 & 0.3891 \\
CME & High-Low & 0.81 & 0.19 & 0.0309 \\
\hline
\end{tabular}

To assess the control that IBL exerts on CME, we performed a regression analysis and the

242 Mann-Whitney U test within the two PK groups (high and low) (Table 5). Although no correlation was observed between IBL and CME in both PK groups, a significant relationship between IBL and CME was found in both PK groups. The low $\mathrm{R}^{2}$ values (0.066 and 0.093 for high and low PK groups, respectively) indicate weak or no correlation between IBL and

$246 \mathrm{CME}$ scores, at least for a linear model. However, the low $p$-values $(<0.05)$ obtained still reflect a real relationship between the predictor (IBL) and the response variable (CME). In other words, there was a positive relationship between the scores in the conceptual model expression and the performance in the inquiry-based learning, with higher average scores in the high prior knowledge group than in the low.

In summary, student scores were overall lower for conceptual model expression than for inquiry-based learning. However, high variability in CME scores was observed between students in the high PK group. Some students with a high rank in prior knowledge still scored poorly at conceptual model expression, indicating that a larger number of previously attended courses does not guarantee a better performance at model conceptualization (though in general higher CME scores were associated with high PK). Similarly, high variability in IBL scores within the low PK group indicates that prior knowledge does not correlate to strong performance in the field (performing experiments, data collection and analysis). 
265 Table 5. Regression analysis between the variables IBL (inquiry-based learning) and CME (conceptual model

266 expression) for the two PK (prior knowledge) groups (high and low). The Mann-Whitney U test to establish the significance of the relationship between variables. s.d. denotes standard deviation.

\begin{tabular}{lllcc}
\hline PK & Variable & Mean (s.d.) & Correlation $\left(\mathbf{R}^{2}\right)$ & Significance $(\boldsymbol{p}<\mathbf{0 . 0 5})$ \\
\hline \multirow{2}{*}{ High } & IBL & $5.38(0.29)$ & 0.066 & 0.0063 \\
& CME & $4.72(0.68)$ & & \\
\multirow{2}{*}{ Low } & IBL & $5.24(0.35)$ & 0.093 & 0.0022 \\
\hline
\end{tabular}

\section{Concluding remarks}

270 Students with a high prior knowledge showed a better performance in the conceptual model expression for the experimental site, while the students in general did not show substantial difficulties implementing the designed inquiry-based learning for the Groundwater Field Course. A positive relationship between the performance in the conceptual model expression and the inquiry-based learning was observed, with students in the high prior knowledge group averaging higher scores in both variables than students in the low prior knowledge group. In both prior knowledge groups, lower scores were observed in the conceptual model expression than in the inquiry-based learning, suggesting that the bottleneck in learning occurs when students are asked to integrate information from various sources in order to construct a conceptual model.

In order to address this students' learning difficulty, instructors have to consider how to implement pedagogical improvements (Sell et al., 2006; Gleeson et al., 2012). The advances in teaching hydrogeology in the last years present a clear bias towards the field and laboratory techniques (Gleeson et al., 2012). While this form of learning helps students develop through inquiry-based learning strategies, this approach ignores the effect of a prior knowledge on the development of conceptual model expression. Lectures often show block diagrams or sketches representing a conceptual model for a hydrogeological system; however, how these conceptual models have been elaborated is often not described in detail. To overcome this issue, elaborating conceptual models through $2 \mathrm{D}$ or $3 \mathrm{D}$ numerical models of aquifer systems have been proposed (Greca and Moreira 2000; Bredehoeft, 2005).

291 However, while numerical models often help develop spatial reasoning abilities (Dickerson et

292 al., 2007) and in some cases with the understanding of the modeled processes, modelling

293 does not help necessarily with the elaboration of a conceptual model $(76 \%$ of the Field

294 Course students were attending a groundwater theoretical and modelling course previously). 
As demonstrated in this study, inquiry-based learning does not directly contribute to the success of conceptual model expression. Thus, specific lessons in the classroom (prior to going to the field) to introduce methodologies for conceptual model expression should be integrated into courses based in active learning. In addition to the development of computational skills (i.e., spatial reasoning abilities), the inclusion of physical models for classroom teaching (prior to going to the field) would aid student elaboration of conceptual models and provide a connection between theoretical knowledge and reality (Rodhe, 2012).

302 This pedagogical combination would aid students as they learn how individual field experiments and the information provided by them can contribute to conceptual models and how we express them.

\section{Acknowledgements}

The author would like to thank the students that participated in the hydrogeology field course and in the survey. Daniel Braun, Matthias Willman, Marius Floriancic, Lucien Biolley,

309 Beatrice Marti, Michael Arnold are thanked for contributing to the field course. The author

310 thanks Jen Nguyen for the enriching discussions. The author declares that any opinion,

311 finding, and conclusion expressed in this study are those of the author and do not reflect the

312 view of his affiliations-institutions.

\section{References}

316 Allen, W., Bosch, O., Kilvington, M., Oliver, J., and Gilbert, M. (2001) Benefits of collaborative learning for environmental management: applying the integrated systems for knowledge management approach to support animal pest control. Environmental Management, 27, 215-223.

Blöschl, G., Carr, G., Bucher, C., Farnleitner, A.H., Rechberger, H., Wagner, W., and Zessner, M., (2012) Promoting interdisciplinary education-the Vienna Doctoral Programme on Water Resource Systems. Hydrology and Earth System Sciences, 16, 457472.

Bransford, J.D., Brown, A., and Cocking, R.R. (1999) How people learn: Brain, mind, experience, and school, Washington, D.C., National Academy Press. 
Coe, N.M., and Smyth, F.M. (2010) Students as tour guides: Innovation in fieldwork assessment. Journal of Geography in Higher Education, 34(1), 125-139.

Cutrim, E., Rudge, D., Kits, K., Mitchell, J., and Nogueira, R. (2006) Changing teaching techniques and adapting new technologies to improve student learning in an introductory meteorology and climate course. Advances in Geosciences, 8, 11-18.

Dickerson, D.L., Penick, J.E., Dawkins, K.R., and Van Sickle, M. (2007) Groundwater in science education. Journal of Science Teacher Education, 18(1), 45-61.

Duit, R., and Glynn, S. (1996) Mental modelling. In G. Welford, J. Osborne and P. Scott (eds) Research in Science Education in Europe, The Falmer Press, London.

Flynn, R., Hunkeler, D., Guerin, C., Burn, C., Rossi, P., and Aragno, M. (2004) Geochemical influences on H40/1 bacteriophage inactivation in glaciofluvial sands. Environmental Geology, 45(4), 504-517.

Fuller, I., Rawlinson, S., and Bevan, R. (2000) Evaluation of student learning experiences in physical geography fieldwork: paddling or pedagogy? Journal of Geography in Higher Education, 24(2), 199-215.

Gates, A., Langford, R., Hodgson, R., and Driscoll, J. (1996) Groundwater simulation apparatus for introductory and advanced courses in environmental geology. Journal of Geoscience Education, 44, 559-64.

Gleeson, T., Allen, D.M., and Ferguson, G. (2012) Teaching hydrogeology: a review of current practice. Hydrology and Earth System Sciences, 16, 2159-2168.

Greca, I.M., and Moreira, M.A. (2000) Mental models, conceptual models, and modelling. International Journal of Science Education, 22, 1-11.

Hakoun, V., Mazzilli, N., Pistre, S., and Jourde, H. (2013) Teaching groundwater flow processes: connecting lecture to practical and field classes. Hydrology and Earth System Sciences, 17, 1975-1984.

Horton, R.E. (1915) Idiosyncrasies of underground water. Proceedings of the Connecticut Society of Civil Engineering, 23-56.

Kali, Y., and Orion, N. (1996) Spatial abilities of high-school students in the perception of geologic structures. Journal of Research in Science Teaching, 33, 369-391.

Kali, Y., Orion, N., and Mazor, E. (1997) Software for assisting high-school students in the spatial perception of geological structures. Journal of Geoscience Education, 45, 10-21.

Laird, T.F.N., Shoup, R., Kuh, G.D., and Schwarz, M.J. (2008) The effects of discipline on deep approaches to student learning and college outcomes. Research in Higher Education, 49(6), 469-494. 
Lee, M.-K. (1998) Hands-on laboratory exercises for an undergraduate hydrogeology course. Journal of Geoscience Education, 46, 433-438.

Lyon, S.W., Walter, M.T., Jantze, E.J., and Archibald, J.A. (2013) Training hydrologists to be ecohydrologists: a "how-you-can-do-it" example leveraging an active learning environment for studying plant-water interaction. Hydrology and Earth System Sciences, 17, 269-279.

Millis, B., and Cottell Jr., P. (1997) Cooperative learning for higher education faculty, Series on higher education, American Council on Education, ORYX Press series on higher education.

Noll, M. (2003) Building bridges between field and laboratory studies in an undergraduate groundwater course. Journal of Geoscience Education, 51, 231-236.

Norman, D. (1983) Some observations on mental models. In D. Gentner and A. Stevens (eds.) Mental models, Lawrence Erlbaum Associates, Hillsdale, N.J., 6-14. experimental site (Bern, Switzerland). MSc Thesis, University of Neuchatel, Switzerland (In French)

Pathirana, A., Koster, J., Jong, E.D., and Uhlenbrook, S. (2012) On teaching styles of water educators and the impact of didactic training. Hydrology and Earth System Sciences, 16(10), 3677-3688.

Pawson, E., and Teather, E.K. (2002) 'Geographical expeditions': Assessing the benefits of a student-driven fieldwork method. Journal of Geography in Higher Education, 26(3), 275289.

Prince, M., and Felder, R. (2006) Inductive teaching and learning methods: Definitions, comparisons, and research bases. Journal of Engineering Education, 95, 123-138.

Rapp, M.C., Fulda, C., Schäfer, W., and Kinzelbach, W. (1998) The dual pumping technique (DPT) for level-determined sampling in fully screened groundwater wells. Journal of Hydrology, 207(3-4), 220-235.

Rodhe, A. (2012) Physical model for classroom teaching in hydrology. Hydrology and Earth System Sciences, 16, 3075-3082.

Rowell, P.M., and Ebbers, M. (2004) Shaping school science: competing discourses in an inquiry-based elementary program. International Journal of Science Education, 26, 915934.

Sanders, L.L. (1998) Teaching hydrogeology to undergraduate and graduate students, Geological Association of America, Abstracts with Programs 30, 305 pp. 
396 Sell, K.S., Herbert, B.E., Stuessy, C.L., and Schielack, J. (2006) Supporting student conceptual model development of complex Earth systems through the use of multiple representations and inquiry. Journal of Geoscience Education, 54(3), 396-407.

She, H.C. (2004) Fostering radical conceptual change through dual-situated learning model. Journal of Research in Science Teaching, 41, 142-164.

Thompson, S. E., Ngambeki, I., Troch, P. A., Sivapalan, M., and Evangelou, D. (2012) Incorporating student-centered approaches into catchment hydrology teaching: A review and synthesis. Hydrology and Earth System Sciences, 16(9), 3263-3278.

Unterbruner, U., Hilberg, S., and Schiffl, I. (2016) Understanding groundwater-students' preconceptions and conceptual change by means of a theory-guided multimedia learning program. Hydrology and Earth System Sciences, 20, 2251-2266.

Van Loon, A.F. (2019) Learning by doing: enhancing hydrology lectures with individual fieldwork projects. Journal of Geography in Higher Education, 43(2), 155-180,

Vicsek, T. (2002) Complexity: The bigger picture. Nature, 418(6894), 131-131.

Vosniadou, S. (2007) The cognitive-situative divide and the problem of conceptual change. Journal of Educational Psychology, 42, 55-66.

Vosniadou, S. (2013) International handbook of research on conceptual change, Routledge, New York, 643 pp.

Wood, W.W., and Wood, W.T. (2014) Fluxes versus the "Frankenstein" model of Earth Science education. Hydrogeology Journal, 22(5), 985-986. 